\title{
Effect of prefeeding lipid on food intake and satiety in man
}

\author{
C P Sepple, N W Read
}

\begin{abstract}
Experiments were carried out in normal volunteers to investigate whether preingestion of lipid reduces food intake. In the first set of experiments, $300 \mathrm{ml}$ beef consomme soup with or without $60 \mathrm{~g}$ margarine was fed to each of six volunteers, followed 20 minutes later by either a low fat solid meal or a preselected appetising meal. Subjects were allowed to eat as much of the meal as they wished. Preingestion of the high fat soup had no significant effect on the consumption of either of the solid meals and did not influence sensations of hunger or fullness. As we have previously shown that prefeeding a fatty soup delays gastric emptying of a subsequent meal, this suggests that gastric distension may play a relatively minor role in regulating food intake. In the second set of experiments, we studied the effect of ingesting either a high fat breakfast (65 g fat, $927 \mathrm{kcal}$ ) or a similar low fat breakfast (8-1 $\mathrm{g}$ fat, $418 \mathrm{kcal})$ on the consumption of a preselected appetising lunch in six healthy volunteers. The high fat breakfast significantly reduced the amount of the meal eaten at lunchtime $(p<0.02)$, the total energy intake from the meal $(p<0.05)$ and the rate of eating $(p<0.05)$ compared with the low fat breakfast. When the subjects were presented with their lunchtime meal they felt significantly less hungry after the high fat breakfast $(p<0 \cdot 05)$. Only a small proportion of either meal (15\% of the high fat meal $v 12 \%$ of the low fat meal) remained in the stomach and plasma glucose concentrations had returned to fasting levels. Plasma triglyceride concentrations were much higher at lunchtime after ingestion of the high fat breakfast $(p<0 \cdot 001)$. The energy intake from the breakfast and lunch combined was not significantly different on the high fat breakfast day, indicating that the energy consumption at lunch compensates for the amount eaten at breakfast. These results are compatible with the concept that the interaction of nutrients with small intestinal receptors may play a part in limiting food intake.
\end{abstract}

Experiments carried out in man and experimental animals suggests that food intake can be inhibited by the presence of nutrients in the small intestine..$^{1-3}$ Infusion of fat into either the jejunum or the ileum, but not into a peripheral vein of human volunteers can decrease food intake and induce early satiety. ${ }^{3+}$ The association of this effect with a delay in gastric emptying might suggest mediation by gastric distension, although this is contradicted by the observation that the continuous feeding that occurs in animals equipped with open gastric fistulae, ${ }^{5}$ can be abolished by infusion of nutrients into the small intestine. ${ }^{1:}$

The aim of these experiments was to investigate whether preingestion of lipid rich foods would effect food intake and induce early satiety in human volunteers. Because we had previously observed that preingestion of a high fat soup delays the emptying of a solid meal eaten 20 minutes later, the first experiment investigated the effect of feeding the same high fat soup on food intake and satiety from a subsequent meal. The second experiment investigated the effect of feeding a high fat breakfast on the amount of food eaten at lunchtime.

\section{Methods}

\section{SUBJECTS}

Each set of experiments was carried out on six healthy male volunteers. All volunteers were within the normal weight range for their age, sex, and height.

EFFECT OF FEEDING A HIGH FAT SOUP ON SATIETY AND INTAKE OF A SOLID MEAL PRESENTED 20 MINUTES LATER

Two sets of experiments were carried out on six volunteers. In the first set of experiments, the meal fed to each volunteer consisted of ratatouille and pasta mixed together $(2 \cdot 2 \mathrm{~g}$ fat/ $100 \mathrm{~g}, 6.2 \mathrm{kcal} / 100 \mathrm{~g}$ ) and drink was limited to $300 \mathrm{ml}$ low calorie orange squash $(0.03 \mathrm{kcal} / \mathrm{ml})$. In the second set of experiments the standard meal was replaced by an appetising meal preselected from an extensive menu by the volunteer, and non-alcoholic fluid was unlimited. Each meal was ingested on two occasions, separated by at least a week, and the two sets of experiments were separated by at least a month.

PROTOCOL

Volunteers were allowed to eat breakfast if they normally did so, providing that they ate it before $830 \mathrm{am}$, and it was the same on both occasions. Midmorning snacks or drinks were not permitted. At $1230 \mathrm{pm}$, the subjects ingested 300 $\mathrm{ml}$ beef soup $(150 \mathrm{ml}$ condensed beef soup, Campbell's, Norfolk) mixed with either $150 \mathrm{ml}$ water (total caloric value $=12 \mathrm{kcal}$ ) or homogenised with $90 \mathrm{ml}$ water and $60 \mathrm{~g}$ margarine (Suma Wholefoods, Halifax) (total caloric value $=455 \mathrm{kcal}$ ). Twenty minutes after consuming the soup, subjects were offered a solid meal and allowed to eat as much as they wished. The order of the two experiments in each of the studies was randomised.

The amount eaten ( $g$ ) and the volume of fluid
Hallamshire Hospit

Sheffield

C P Sepple

Correspondence to: $\operatorname{Dr} C \mathrm{P}$

Sepple.

Accepted for publication

10 May 1989
Sub-department

Physiology and Nutrition, 
consumed was assessed by weighing the containers before and after consumption and the caloric value of the meal was calculated from these values. The time taken to complete the meal was recorded and the average rates of eating and drinking calculated. Subjective sensations such as hunger, fullness, and nausea were recorded by means of visual analogue questionnaires, which were completed by the subjects at 10 minute completed the first questionnaire just before they consumed the soup and the last, 50 minutes after they were presented with their solid meal.

EFFECT OF EATING A HIGH FAT BREAKFAST ON SATIETY AND INTAKE OF A MEAL

CONSUMED AT LUNCHTIME

Paired studies were carried out on each of six volunteers, which were separated by a week. On the nights before the studies, volunteers consumed a similar light dinner; food was prohibited after $930 \mathrm{pm}$. At 830 am on the morning of the experiment, volunteers ate either a high fat breakfast (caloric value $=927 \mathrm{kcal}$, fat content $=$ $65 \mathrm{~g}$, total weight $=287 \mathrm{~g}$ ), or a low fat breakfast (caloric value $=418 \mathrm{kcal}$, fat content $=8 \cdot 1 \mathrm{~g}$, total weight $=283 \mathrm{~g}$ ). The two breakfasts were similar in appearance and virtually identical in carbohydrate and protein content. The low fat breakfast consisted of very lean bacon, scrambled egg white, toast and a drink of skimmed milk, whereas the high fat breakfast was composed of streaky bacon, scrambled whole egg, toast spread with $30 \mathrm{~g}$ butter and a drink of full cream milk. From 850 am until 1230 pm, subjects were free to leave the department, but care was taken to ensure that they had no further food or drink and their activities were similar on both study days. At $1230 \mathrm{pm}$, they were presented with an appetising meal, which they had preselected from a menu. They were invited to consume as much food and non-alcoholic fruit juice as they wished. The amount of food and drink consumed, the energy intake, the rates of eating and drinking and the time taken to complete the meal were measured. Subjective sensations were recorded on visual analogue scales, completed at five minute intervals from 830 am until 850 am and then at half hourly intervals until 1230 and at 10 minute intervals until 1320 pm.

\section{EFFECT OF A HIGH FAT BREAKFAST ON GASTRIC EMPTYING, PLASMA GLUCOSE CONCENTRATIONS AND SERUM TRIGLYCERIDE LEVELS}

Paired studies were carried out in six volunteers. On one occasion, subjects consumed the high fat intervals for a total of 70 minutes. Volunteers

breakfast and on the other occasion, they ate the low fat breakfast.

At $830 \mathrm{am}$, subjects were given their breakfast which was labelled with $1.85 \mathrm{MBq}$ of technetium sulphur colloid (99-m Tc). Subjects were then positioned under a scintigraphic gamma camera in a semisupine position. Gastric emptying of the breakfast was monitored for four hours by scintigraphy. Blood samples were taken at regular intervals via an indwelling venous catheter. Plasma glucose concentrations were measured at 15 minute intervals and serum triglyceride concentrations were measured at hourly intervals throughout the study.

\section{STATISTICAL ANALYSIS}

The statistical significance of the difference in the results obtained during the test and control studies was assessed by the paired $t$ test.

\section{Results}

EFFECT OF PREFEEDING A HIGH FAT SOUP ON FOOD INTAKE AND SATIETY OF A SOLID MEAL PRESENTED 20 MINUTES LATER Preingestion of either the high fat soup or the low fat soup did not influence the amount of either the standard low calorie meal or the appetising meal ingested, the time taken to complete either meal and the rate of ingestion (Table I). Subjects drank more fluid after ingestion of the high fat soup with preselected appetising meal $(p<0 \cdot 01)$, but not with the standard meal.

If the soup is included in the sum of total energy intake, then the calorie intake from the standard meal during the high fat study was significantly larger than during the corresponding control study $(p<0.01)$. Irrespective of the nature of the soup, the energy intake from the preselected appetising meal was greater than the energy intake from the standard meal $(\mathrm{p}<0.01)$.

Preingestion of either high fat or low fat soup did not influence scores of fullness or any other sensations in either experiment.

\section{EFFECT OF FEEDING A HIGH FAT} BREAKFAST ON FOOD INTAKE AND SATIETY OF AN APPETISING MEAL FED AT

LUNCHTIME

Ingestion of the high fat breakfast significantly reduced the amount eaten at lunchtime $(p<0 \cdot 02)$, the energy intake from that meal (food and drink, $p<0.05$ ) and slowed the rate of consumption of lunch $(p<0.05)$, but did not influence the time taken for subjects to complete the meal (Table II, Fig 1).

The overall energy intake from breakfast and

TABLE I Effect of high fat soup on food intake and satiety of a standard low calorie meal and an appetising meal

\begin{tabular}{|c|c|c|c|c|}
\hline & \multicolumn{2}{|c|}{ Ratatouille meal } & \multicolumn{2}{|c|}{ Preselected appetising meal } \\
\hline & Control & Test & Control & Test \\
\hline Meal completion time $(\min )$ & $13(2)$ & $11(2)$ & $17(2)$ & $15(2)$ \\
\hline Total amount eaten $(\mathrm{g})$ & $549(72)$ & $440(70)$ & $989(162)$ & $885(105)$ \\
\hline Rate of eating ( $\mathrm{g} / \mathrm{min})$ & $43(3)$ & $42(4)$ & $58(6)$ & $62(8)$ \\
\hline Energy value of food $(\mathrm{kcal})$ & $357(56)$ & $305(48)$ & $1658(269)$ & $1536(264)$ \\
\hline Total energy intake (kcal) (meal + soup) & $378(55)$ & $770(48)$ & $1680(270)$ & $2004(262)$ \\
\hline
\end{tabular}

TABLE II Effect of a high fat breakfast on feeding behaviour and satiety of a lunchtime meal

\begin{tabular}{lcll}
\hline & $\begin{array}{l}\text { High fat } \\
\text { breakfast }\end{array}$ & $\begin{array}{l}\text { Low fat } \\
\text { breakfast }\end{array}$ & p value \\
\hline Amount eaten $(\mathrm{g})$ & $790(82)$ & $1047(94)$ & $\mathrm{p}<0.02$ \\
Energy intake $(\mathrm{kcal})$ & $944(94)$ & $1284(113)$ & $\mathrm{p}<0.05$ \\
Rate of eating $(\mathrm{g} / \mathrm{min})$ & $52(4)$ & $62(5)$ & $\mathrm{p}<0.05$ \\
Daily energy intake $(\mathrm{kcal})$ & $1871(94)$ & $1702(113)$ & $\mathrm{NS}$ \\
\hline
\end{tabular}



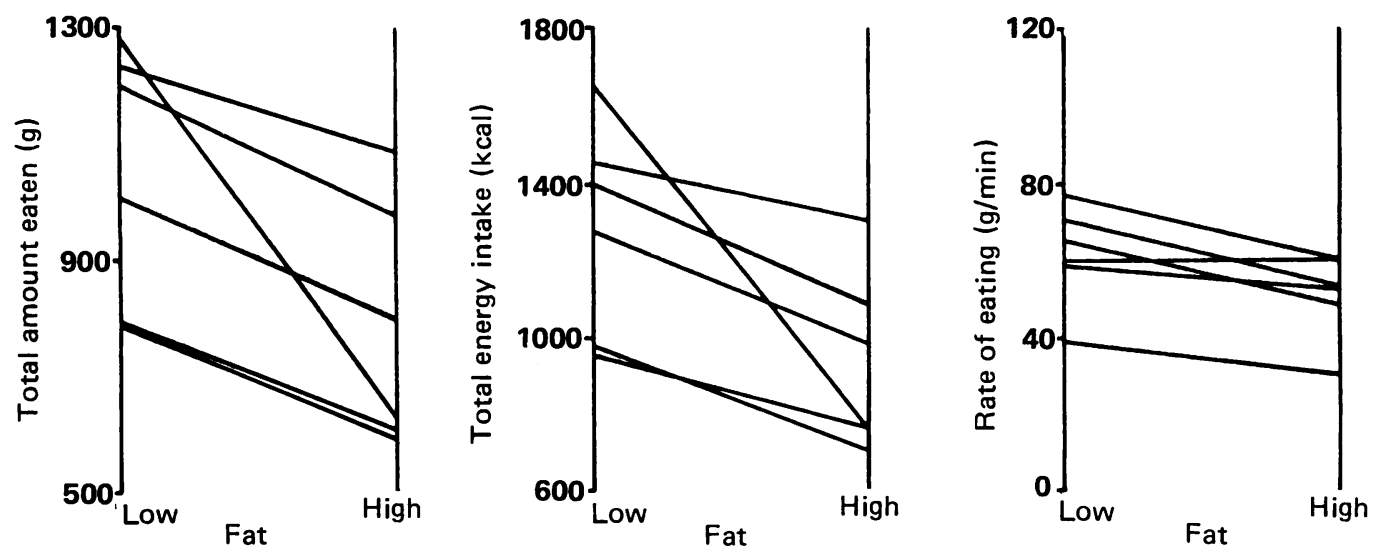

Figure 1: Individual results from the six volunteers showing the effect of prefeeding a low fat breakfast and a high fat breakfast on the total amount eaten (left), the total energy intake (centre) and the rate of ingestion (right) of a lunchtime meal.

lunch combined was not significantly affected by the nature of the breakfast (Table II), suggesting that the low energy intake at lunch compensated for the high energy intake at breakfast.

Subjects felt significantly more full $(\mathrm{p}<0.05)$ five minutes after starting the high fat breakfast than they did five minutes after the low fat breakfast (Fig 2). More important, they felt less hungry when the lunchtime meal was presented to them after eating the high fat breakfast compared with the low fat breakfast $(p<0.05)$. There were no other statistical differences in any of the other sensations recorded.

\section{EFFECT OF FEEDING THE HIGH FAT BREAKFAST ON GASTRIC EMPTYING, PLASMA GLUCOSE AND SERUM TRIGLYCERIDE CONCENTRATIONS}

There was no significant difference in the half time for gastric emptying of the high fat breakfast to empty compared with the low fat breakfast to empty (124 (14.5) min (mean (SEM)) $v$ $119(14 \cdot 1))$. After four hours, there was $15(4) \%$ of the high fat breakfast remaining in the stomach compared with $12(4 \cdot 5) \%$ of the low fat breakfast.

The glucose profiles followed a similar pattern after both breakfasts and had returned to fasting levels within 90 minutes of ingesting the breakfasts (Fig 3). The triglyceride concentrations, however, significantly increased after the high fat breakfast compared with the levels after the low fat breakfast and were still raised four hours after ingestion of the high fat breakfast (Fig 3).

\section{Discussion}

The effects of prefeeding lipid on subsequent ingestion of food depends upon how the lipid is given in relation to the test meal. Prefeeding lipid in the form of a soup before a solid meal did not significantly reduce the amount of the solid meal eaten, irrespective of whether this was a standard meal or a preselected appetising meal. The total energy intake (meal+soup) was greater when the high fat soup was consumed compared with the low fat soup and after the appetising meal compared with the standard meal, although subjects ate to similar levels of fullness. Thus the results indicate that subjects do not compensate for changes in energy density of a meal by altering the amount of food eaten, and that food intake from a single meal may be influenced more by hedonistic factors. The observation that prefeeding a high fat soup delays gastric emptying, but does not influence ingestion of the subsequent meal might suggest that gastric distension is a relatively unimportant factor in regulating normal eating behaviour. Alternatively, Booth ${ }^{6}$ and other workers ${ }^{7}$ have suggested that satiety is a conditioned reaction and therefore the volunteers may have consumed similar amounts as a result of past experience of the meal.

Different results were obtained if the lipid was
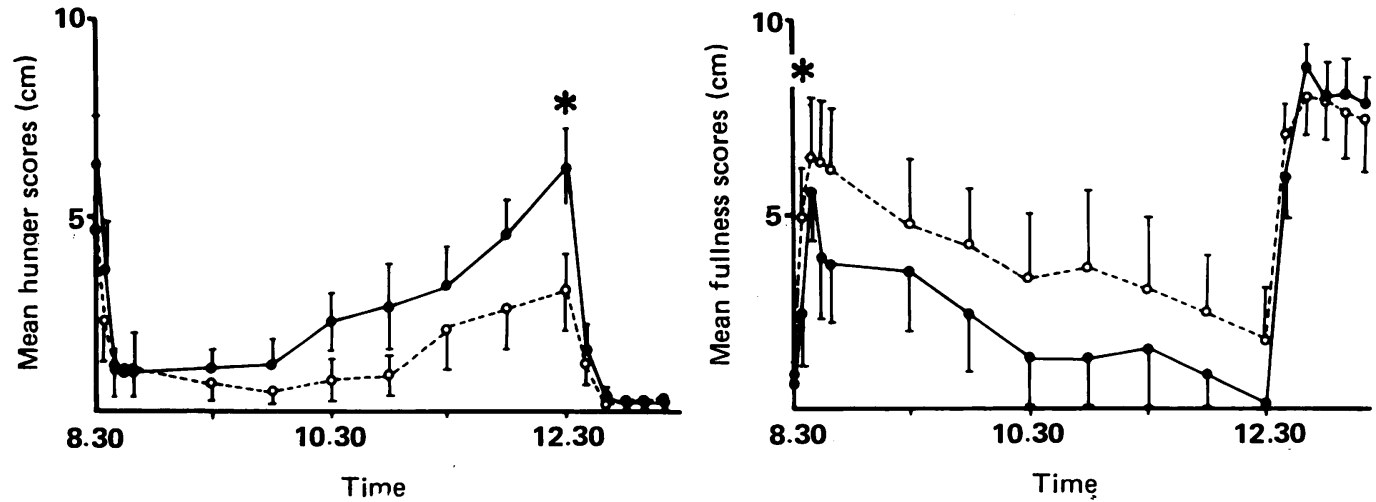

Figure 2: Subjective sensations of hunger (left) and fullness (right), experienced by the volunteers before and after ingestion of the lunchtime meal. The dotted line represents scores after the high fat breakfast and the solid line represents scores after the low fat breakfast. Results are expressed as mean $(S E M)(n=6)$. 

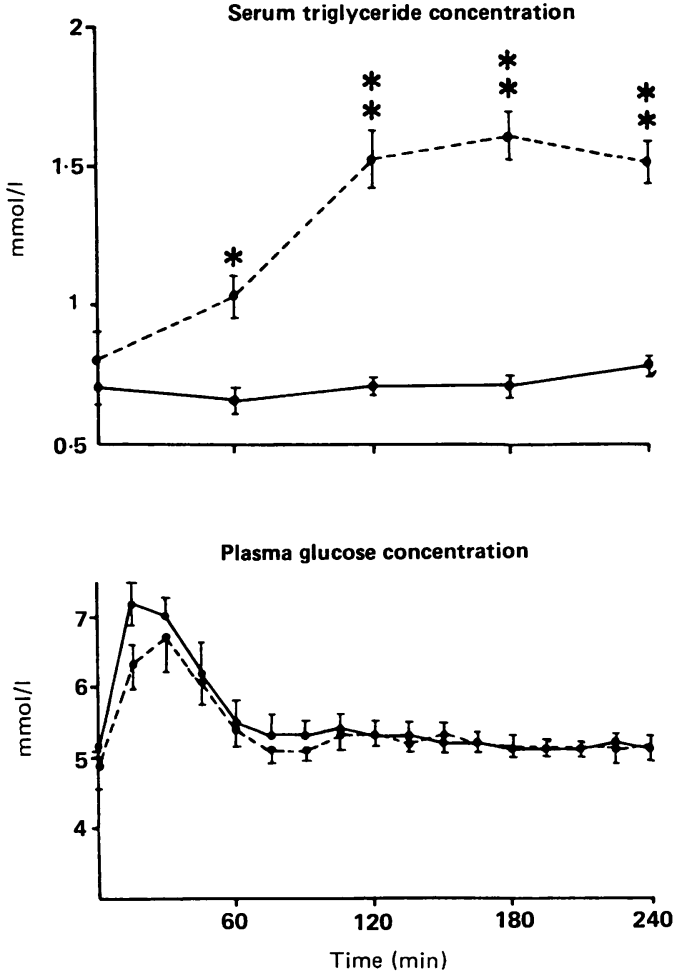

Figure 3: Serum concentration of triglyceride (top) and plasma concentration of glucose (bottom) after consuming the high fat breakfast (dotted line) and the low fat breakfast (solid line). Results are expressed as mean $(S E M)(n=6)\left({ }^{\star}=p<0 \cdot 01\right.$, $\star \star=p<0.001)$.

incorporated in a cooked breakfast; this reduced the volume and the energy intake from a lunch eaten four hours later. Also when subjects had consumed the fatty breakfast they felt less hungry immediately before lunch. This result was not related to differences in gastric emptying of the two breakfasts from the stomach. Very little of either breakfast remained in the stomach to influence food ingestion four hours later. Neither was it related to differences in plasma glucose concentrations, as they had attained fasting levels by 90 minutes after ingestion of either breakfast. Serum triglyceride concentrations, however, were still raised four hours after the high fat breakfast, suggesting continued absorption of fat at that time. Thus, the data are compatible with the limitation of energy intake by interaction of fat with small intestinal receptors. It is unlikely that the presence of plasma lipid or oxidation products are respons- ible for the suppression of food intake, as we have previously shown that intravenous infusion of fat emulsion failed to influence energy intake. The reason why the high fat soup failed to reduce energy intake, whereas the high fat breakfast reduced energy intake at lunchtime could be explained by the possibility that after 20 minutes, insufficient amounts of the soup would have emptied from the stomach to interact with intestinal receptors regulating food intake.

The data from the breakfast experiments indicate that, at least in the short term, normal subjects possess mechanisms that attempt to normalise daily energy intake. This is in agreement with other recent data, in which subjects increased the amount eaten two hours after ingesting a low energy dense lunch compared with a high energy dense lunch. ${ }^{x}$ Studies carried out over longer periods of time, suggest that there is little or no compensation in the amount eaten if the fat content of a diet is changed, but the appearance and palatability remain similar. ${ }^{9-11}$ It is possible that in the long term, the subject may be able to override gastrointestinal signals and become conditioned to a higher energy intake: ${ }^{6}$ alternatively with continued exposure to a high energy intake, intestinal nutrient receptors or receptors sensitive to CCK released from the small intestine by exposure to fat, may become down regulated.

1 Gibbs J, Maddison S, Rolls E. Satiety role of the small intestine examined in sham feeding rhesus monkeys. $\mathcal{F}$ Comp Physio Psychol 1981; 95: 1003-15.

2 Liebling D, Eisner J, Gibbs J, Smith GP. Intestinal satiety in rats. F Comp Physiol Psychol 1975; 89: 955-65.

3 Welch I, Saunders K, Read NW. Effect of ileal and intravenous infusions of fat emulsions on feeding and satiety in human volunteers. Gastroenterol 1985; 89: 1293-7.

4 Welch I, Sepple CP, Read NW. Comparison of the effects on satiety and eating behaviour by infusion of lipid emulsion into different regions of the small intestine. Gut 1988; 29 . into differ 11 .

5 Smith GP, Gibbs J. Postprandial satiety. In: Sprague JM Epstein AN, eds. Progress in psychobiology and physiological Epstein AN, eds. Progress in psychobiology and physiologic
psychology. New York: Academic Press, 1979: 179-242.

6 psychology. New York: Academic Press, 197i: 179-242. Psychosom Med 1977; 39: 76-81.
Poth DA. Satiety and appetite

7 Stunkard AJ. Satiety is a conditioned reflex. Psychosom Med 1975; 37: 383-7.

8 Hill AJ, Leathwood PD, Blundell JE. Some evidence for shor term caloric compensation in normal weight human subjects: The effects of high and low energy meals on hunger, food preferences and food intake. Hum Nutr Appl Nutr 1987, 41: $244-57$.

9 Duncan K, Bacon JA, Weisner RL. The effects of high and low energy density diets on satiety, energy intake and eating low energy density diets on satiety, energy intake and eating
time of obese and non-obese subjects. Am f Clin Nutr 1983; time of obese

10 Glueck CJ, Hastings MM, Allen C, et al. Sucrose polyester and covert caloric dilution. Am f Clin Nutr 1982; 35: 1352-9.

11 Lissner L, Roe D. Dietary fat and the regulation of energy intake in human subjects. Am F Clin Nutr 1987; 46: 886-92. 